\title{
Intravenous AICAR administration reduces hepatic glucose output and inhibits whole body lipolysis in type 2 diabetic patients
}

\author{
H. Boon • M. Bosselaar • S. F. E. Praet • E. E. Blaak • \\ W. H. M. Saris - A. J. M. Wagenmakers • S. L. McGee • \\ C. J. Tack • P. Smits • M. Hargreaves • L. J. C. van Loon
}

Received: 24 April 2008 / Accepted: 2 July 2008 / Published online: 16 August 2008

(C) The Author(s) 2008

\begin{abstract}
Aims/hypothesis The 5'-AMP-activated protein kinase (AMPK) pathway is intact in type 2 diabetic patients and is seen as a target for diabetes treatment. In this study, we aimed to assess the impact of the AMPK activator 5aminoimidazole-4-carboxamide riboside (AICAR) on both glucose and fatty acid metabolism in vivo in type 2 diabetic patients.
\end{abstract}

H. Boon $(\bowtie) \cdot$ E. E. Blaak • W. H. M. Saris • L. J. C. van Loon Department of Human Biology, Nutrition and Toxicology

Research Institute Maastricht (NUTRIM), Maastricht University, P. O. Box 616, 6200 MD Maastricht, the Netherlands

e-mail: H.Boon@HB.unimaas.nl

M. Bosselaar $\cdot$ C. J. Tack $\cdot$ P. Smits

Department of General Internal Medicine, Radboud University

Nijmegen Medical Centre,

Nijmegen, the Netherlands

S. F. E. Praet • L. J. C. van Loon

Department of Movement Sciences, Nutrition and Toxicology Research Institute Maastricht (NUTRIM), Maastricht University,

Maastricht, the Netherlands

\section{A. J. M. Wagenmakers}

School of Sport and Exercise Sciences,

University of Birmingham,

Birmingham, UK

\section{S. L. McGee $\cdot$ M. Hargreaves}

Department of Physiology, University of Melbourne,

Melbourne, Victoria, Australia

\section{P. Smits}

Department of Pharmacology and Toxicology,

Radboud University Nijmegen Medical Centre,

Nijmegen, the Netherlands
Methods Stable isotope methodology and blood and muscle biopsy sampling were applied to assess blood glucose and fatty acid kinetics following continuous i.v. infusion of AICAR $\left(0.75 \mathrm{mg} \mathrm{kg}^{-1} \mathrm{~min}^{-1}\right)$ and/or $\mathrm{NaCl}(0.9 \%)$ in ten male type 2 diabetic patients (age $64 \pm 2$ years; BMI $\left.28 \pm 1 \mathrm{~kg} / \mathrm{m}^{2}\right)$.

Results Plasma glucose rate of appearance $\left(R_{\mathrm{a}}\right)$ was reduced following AICAR administration, while plasma glucose rate of disappearance $\left(R_{\mathrm{d}}\right)$ was similar in the AICAR and control test. Consequently, blood glucose disposal $\left(R_{\mathrm{d}}\right.$ expressed as a percentage of $\left.R_{\mathrm{a}}\right)$ was increased following AICAR infusion $(p<0.001)$. Accordingly, a greater decline in plasma glucose concentration was observed following AICAR infusion $(p<0.001)$. Plasma NEFA $R_{\mathrm{a}}$ and $R_{\mathrm{d}}$ were both significantly reduced in response to AICAR infusion, and were accompanied by a significant decline in plasma NEFA concentration. Although AMPK phosphorylation in skeletal muscle was not increased, we observed a significant increase in acetyl-CoA carboxylase phosphorylation $(p<0.001)$.

Conclusions/interpretation The i.v. administration of AICAR reduces hepatic glucose output, thereby lowering blood glucose concentrations in vivo in type 2 diabetic patients. Furthermore, AICAR administration stimulates hepatic fatty acid oxidation and/or inhibits whole body lipolysis, thereby reducing plasma NEFA concentration.

\section{Trial registration: ISRCTN31384581}

Funding: The study was funded by the Dutch Diabetes Research Foundation. S. L. McGee is a National Health and Medical Research Council (NHMRC) Peter Doherty Fellow (400446). 
Keywords AICAR · AMPK · Diabetes · Glucose · NEFA .

Non-esterified fatty acids

Abbreviations
$\begin{array}{ll}\text { ACC } & \text { acetyl-CoA carboxylase } \\ \text { AS160 } & \text { phospho-Akt substrate of } 160 \mathrm{kDa} \\ \text { AICAR } & \text { 5-aminoimidazole-4-carboxamide riboside } \\ \text { AMPK } & \text { 5'-AMP-activated protein kinase } \\ \text { ERK } & \text { extracellular signal-regulated protein kinase } \\ \text { GSK } & \text { glycogen synthase kinase } \\ \text { HDAC5 } & \text { histone deacetylase } 5 \\ R_{\mathrm{a}} & \text { rate of appearance } \\ R_{\mathrm{d}} & \text { rate of disappearance }\end{array}$

\section{Introduction}

5'-AMP-activated protein kinase (AMPK) is a key enzyme in the regulation of energy metabolism. It acts as a cellular energy sensor, and is activated by metabolic stress, such as hypoxia, and muscle contraction [1]. AMPK controls both fatty acid and carbohydrate metabolism [2-6] by increasing skeletal muscle glucose $[2,4,6,7]$ and fatty acid $[2,3]$ uptake and/or oxidation, suppression of hepatic glucose output [4] and inhibition of adipose tissue lipolysis $[5,8]$. Importantly, AMPK regulates these processes in an insulin-independent manner. The AMPK pathway appears largely intact in obese and/or type 2 diabetic rodents [3, 9-12] and humans [5, 13-16]. Consequently, AMPK is regarded as a potential target for the treatment of type 2 diabetes.

AMPK is activated by 5-aminoimidazole-4-carboxamide riboside (AICAR) in skeletal muscle [2-4], adipocytes [8] and hepatocytes [17]. Although this agent has been widely used to study the metabolic effects of AMPK activation in rodents $[2-4,8,17]$, studies investigating the effect of AICAR on AMPK-regulated substrate metabolism in human tissue are scarce $[13,14,18]$. A recent study investigated the effect of AICAR infusion $\left(10 \mathrm{mg} \mathrm{kg}^{-1} \mathrm{~h}^{-1}\right)$ on skeletal muscle 2-deoxyglucose uptake in young, healthy males [19]. However, no studies have examined the impact of AICAR on whole body glucose or fatty acid metabolism in humans. Furthermore, the effects of AICAR administration in type 2 diabetic patients remain to be established.

We hypothesise that i.v. AICAR administration in type 2 diabetic patients reduces both plasma glucose and NEFA concentrations by stimulating blood glucose disposal, lowering hepatic glucose output, and inhibiting adipose tissue lipolysis. In the present study, we combine stable isotope methodology with blood and muscle biopsy sampling to determine the effect of i.v. AICAR administra- tion on blood glucose and fatty acid kinetics in vivo in type 2 diabetic patients.

\section{Methods}

Participants Ten male type 2 diabetic patients (age $64 \pm$ 2 years, BMI $28 \pm 1 \mathrm{~kg} / \mathrm{m}^{2}$, body fat $29 \pm 1 \%, \mathrm{HbA}_{1 \mathrm{c}} 6.6 \pm$ $0.2 \%$, duration of diabetes $7 \pm 1$ years) were selected to participate in this study. Exclusion criteria were severe diabetes complications, impaired renal or liver function, cardiovascular complications, severe obesity (BMI $>35 \mathrm{~kg} / \mathrm{m}^{2}$ ), gout, participation in any regular exercise programme and/ or exogenous insulin therapy. All participants were sedentary and taking metformin, sulfonylurea derivatives and/or thiazolidinediones. Skinfold thickness was measured twice using skinfold calipers at the triceps, biceps, subscapular and suprailiacal region. The sum of the skinfold thicknesses was used to calculate body fat percentage [20]. Volunteers were informed about the nature and risks of the experimental procedures before their informed consent was obtained. The study was carried out in accordance with the principles of the Declaration of Helsinki and was approved by the Medical Ethics Committee of the Radboud University Nijmegen Medical Centre (Nijmegen, The Netherlands).

Experimental trials Each volunteer participated in two experimental tests, one in which AICAR $\left(0.75 \mathrm{mg} \mathrm{kg}^{-1} \mathrm{~min}^{-1}\right)$ was infused and one in which only $\mathrm{NaCl}(0.9 \%)$ was infused to ensure equal volume administration. The order of the tests was randomised, and tests were separated by at least 2 weeks. Each test consisted of 90 min of resting measurements, during which $\mathrm{NaCl}(0.9 \%)$ was infused, followed by either $120 \mathrm{~min}$ of AICAR or $\mathrm{NaCl}(0.9 \%)$ infusion. $\left[2,2-{ }^{2} \mathrm{H}_{2}\right] \mathrm{Palmitate}$ and $\left[6,6-{ }^{2} \mathrm{H}_{2}\right]$ glucose were infused intravenously, with arterialised blood samples collected at $15 \mathrm{~min}$ intervals. Muscle biopsy samples from the vastus lateralis muscle were collected before the start of the AICAR test and immediately after the last blood sample was obtained, at which time AICAR was still being continuously infused.

Medication, diet and physical activity prior to testing All participants discontinued their use of blood glucoselowering medication for 4 days prior to the tests and abstained from strenuous physical activity for 2 days prior to testing. In addition, they were asked to record their dietary intake during the 2 days prior to the first test and to repeat this diet prior to the second test. Consumption of caffeine-containing food and beverages was not allowed for $24 \mathrm{~h}$ prior to the tests, as caffeine is a potent adenosine receptor antagonist [21]. The evening prior to each test, all 
participants consumed the same standardised meal $(42 \mathrm{~kJ} / \mathrm{kg}$; containing $61 \%$ of energy as carbohydrate, $24 \%$ as fat and $15 \%$ as protein).

Protocol After an overnight fast, participants arrived at the research centre at 08:00 hours by car or public transport. Two Teflon catheters (Baxter, Utrecht, The Netherlands) were inserted into separate veins of one forearm for isotope and AICAR and/or $\mathrm{NaCl}(0.9 \%)$ infusion. To obtain arterialised venous blood, a third catheter was inserted into a superficial dorsal hand vein of the contralateral arm, after which the hand was warmed in a hot box that circulated air at $55^{\circ} \mathrm{C}$, to achieve adequate arterialisation [22]. In the AICAR test, a percutaneous muscle biopsy sample was taken from the vastus lateralis muscle after the participant had rested for $30 \mathrm{~min}$ in the supine position. After an additional $15 \mathrm{~min}$ of rest, participants were administered a single i.v. primed infusion of $\left[6,6-{ }^{2} \mathrm{H}_{2}\right]$ glucose $(13.5 \mu \mathrm{mol} /$ $\mathrm{kg}$; Cambridge Isotope Laboratories, Andover, MA, USA). Thereafter, continuous infusions of $\left[6,6-{ }^{2} \mathrm{H}_{2}\right]$ glucose $\left(0.3 \mu \mathrm{mol} \mathrm{kg}{ }^{-1} \mathrm{~min}^{-1}\right)$ and $\left[2,2-{ }^{2} \mathrm{H}_{2}\right]$ palmitate $(0.035 \mu \mathrm{mol}$ $\mathrm{kg}^{-1} \mathrm{~min}^{-1}$; Cambridge Isotope Laboratories) were started $(t=0 \mathrm{~min})$ via a calibrated IVAC pump (CNA Medical, Royse City, TX, USA); $\mathrm{NaCl}(0.9 \%)$ was infused for 90 min via an IVAC pump. In the AICAR test, an AICAR infusion $\left(0.75 \mathrm{mg} \mathrm{kg}^{-1} \mathrm{~min}^{-1}\right.$; Toronto Research Chemicals, Toronto, ON Canada) was started at $t=90 \mathrm{~min}$ and continued for $120 \mathrm{~min}$, whereas in the control trial an $\mathrm{NaCl}$ infusion was continued at an infusion rate equal to that in the AICAR trial. A second muscle biopsy sample was taken immediately after the last blood sample was obtained but under continued AICAR infusion.

Blood sample analysis Blood samples $(8 \mathrm{ml})$ were collected in EDTA-containing tubes and immediately centrifuged at $1,000 \mathrm{~g}$ for $10 \mathrm{~min}$ at $4^{\circ} \mathrm{C}$. Aliquots of plasma were immediately frozen in liquid nitrogen and stored at $-80^{\circ} \mathrm{C}$. Plasma glucose (Roche, Basel, Switzerland), lactate (Wako Chemicals, Neuss, Germany), NEFA (Wako Chemicals), glycerol (Roche Diagnostics, Indianapolis, IN, USA) and triacylglycerol (Sigma Diagnostics, St Louis, MO, USA) concentrations were analysed with a COBAS semi-automatic analyser (Roche). Plasma insulin was measured by radioimmunoassay (Linco, St Charles, MO, USA). Blood HbA 1 c was analysed by HPLC (Variant II; Bio-Rad, Munich, Germany). For determination of plasma palmitate and NEFA kinetics, NEFA were extracted, isolated by thinlayer chromatography and derivatised to their methyl esters. Isotope enrichment of palmitate was analysed by GC-MS (Agilent, Little Falls, DE, USA). Plasma palmitate concentration was determined on an analytical GC with flame ionisation detection using nonadecaenoic acid as the internal standard, and was found to constitute $23.9 \pm$
$0.18 \%$ of total NEFA. Following derivatisation, plasma $\left[6,6-{ }^{2} \mathrm{H}_{2}\right]$ glucose enrichment was determined by electron ionisation GC-MS (Agilent). Palmitate and glucose tracer concentrations in the infusates averaged $2.34 \pm 0.03$ and $37.3 \pm 0.10 \mathrm{mmol} / \mathrm{l}$, respectively, in the AICAR test vs $2.27 \pm$ 0.06 and $37.3 \pm 0.06 \mathrm{mmol} / 1$ in the control test. Therefore, the exact palmitate and glucose tracer infusion rates averaged $27 \pm 1$ and $272 \pm 7 \mathrm{nmol} \mathrm{kg}{ }^{-1} \min ^{-1}$, respectively, in the AICAR test vs $28 \pm 1$ and $272 \pm 8 \mathrm{nmol} \mathrm{kg}^{-1} \mathrm{~min}^{-1}$ in the control test. Plasma AICAR concentrations were determined by HPLC, with UV detection set at $260 \mathrm{~nm}$, using a $200 \times 4.6 \mathrm{~mm} 5 \mu \mathrm{m}$ Hypersil BDS C18 column (ThermoFisher, Waltham, MA, USA). The mobile phase consisted of methanol, $10 \mathrm{mmol} / \mathrm{l}$ tetrabutylammonium hydrogen sulphate and $5 \mathrm{mmol} / 1 \mathrm{~K}_{2} \mathrm{HPO}_{4}$, pH 8.2 (20:80, vol./vol.).

Tracer calculations Rate of appearance $\left(R_{\mathrm{a}}\right)$ and rate of disappearance $\left(R_{\mathrm{d}}\right)$ of palmitate and glucose were calculated using the single-pool non-steady-state Steele equations adapted for stable isotope methodology:

$R_{\mathrm{a}}=\frac{F-V\left[\left(C_{2}+C_{1}\right) / 2\right]\left[\left(E_{2}-E_{1}\right) /\left(t_{2}-t_{1}\right)\right]}{\left[\left(E_{2}+E_{1}\right) / 2\right]}$

$R_{\mathrm{d}}=R_{\mathrm{a}}-V\left(\frac{C_{2}-C_{1}}{t_{2}-t_{1}}\right)$

where $F$ is the infusion rate (in $\mu \mathrm{mol} \mathrm{kg} \mathrm{kg}^{-1} \min ^{-1}$ ), $V$ is distribution volume for palmitate or glucose (40 and $160 \mathrm{ml} / \mathrm{kg}$, respectively), $C_{1}$ and $C_{2}$ are palmitate or glucose concentrations $(\mathrm{mmol} / \mathrm{l})$ at time $1\left(t_{1}\right)$ and $2\left(t_{2}\right)$, respectively, and $E_{2}$ and $E_{1}$ are the plasma palmitate or glucose enrichments (tracer/tracee ratios, TTR) at $t_{1}$ and $t_{2}$, respectively.

Muscle sample analysis Muscle samples were dissected, freed from any visible non-muscle material and immediately frozen in liquid nitrogen. Approximately $30 \mathrm{mg}$ of muscle was homogenised in ten volumes of homogenisation buffer $(50 \mathrm{mmol} / 1$ Tris $\mathrm{pH} 7.5,1 \mathrm{mmol} / 1$ EDTA, $1 \mathrm{mmol} / \mathrm{l}$ EGTA, $50 \mathrm{mmol} / 1 \mathrm{NaF}, 5 \mathrm{mmol} / 1 \mathrm{Na}_{4} \mathrm{P}_{2} \mathrm{O}_{7}, 10 \%$ [wt/vol.] glycerol, 1\% [wt/vol.] Triton X-100, $1 \mathrm{mmol} /$ 1 DTT, protease inhibitor cocktail). Samples were centrifuged at $1,000 \mathrm{~g}$ for $5 \mathrm{~min}$, and then the supernatant fractions were assayed for total protein and $50 \mu \mathrm{g}$ of protein was resolved by SDS-PAGE and transferred to nitrocellulose membranes. Membranes were incubated with antibodies for pT172 AMPK $\alpha 1$, AMPK $\alpha 2$, pS79 acetyl-CoA carboxylase (ACC), ACC, phospho-Akt substrate of 160 kDa (AS160), AS160, pT202/Y204 extracellular signal-regulated protein kinase (ERK), ERK, pS21/9 


\section{a}
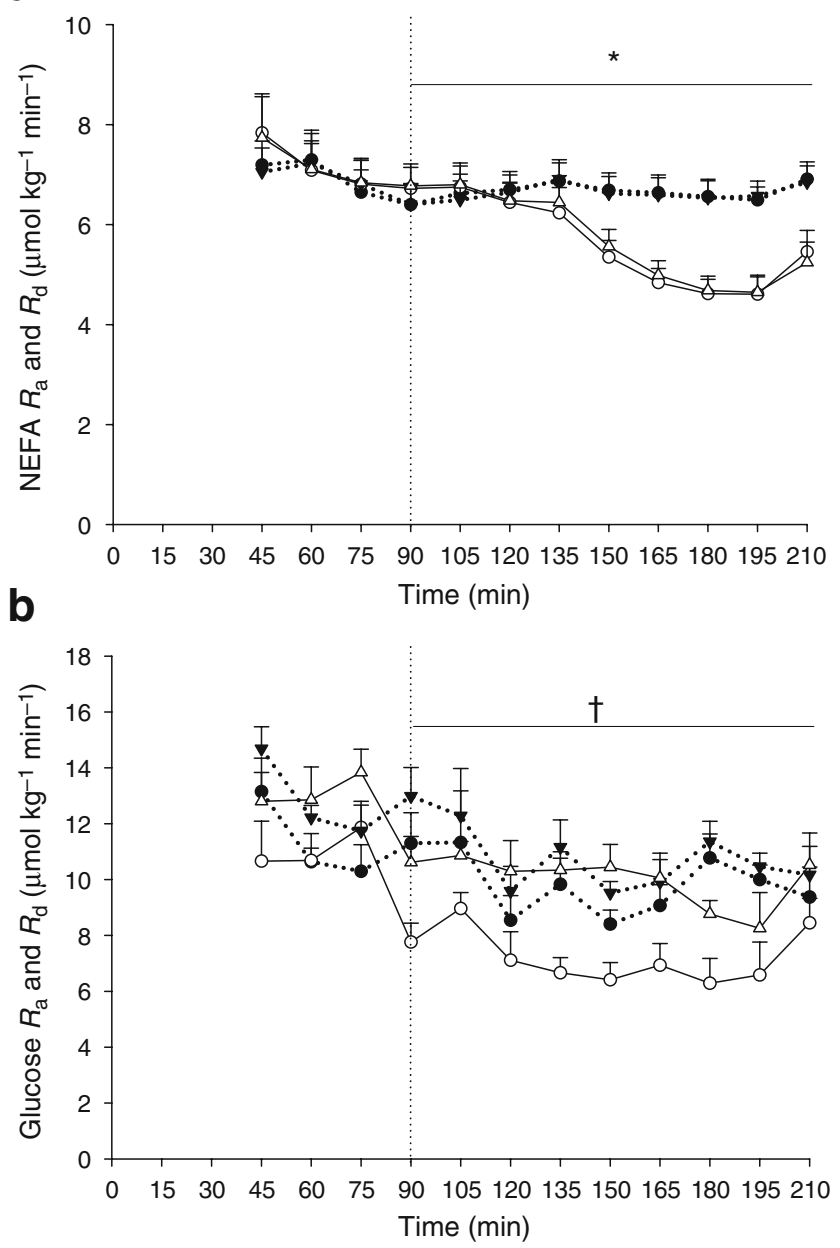

Fig. 1 Plasma NEFA (a) and plasma glucose (b) tracer kinetics as determined during the administration of i.v. AICAR $\left(0.75 \mathrm{mg} \mathrm{kg}^{-1} \mathrm{~min}^{-1}\right)$ and/or $\mathrm{NaCl}(0.9 \%)$. In the AICAR test, the AICAR infusion was started at $t=90 \mathrm{~min}$. White symbols represent data from the AICAR test, black symbols represent data from the control test. Circles represent $R_{\mathrm{a}}$, triangles represent $R_{\mathrm{d}}$. The dotted line indicates the beginning of AICAR infusion in the AICAR trial. Values are means \pm SEM. * Significantly lower plasma NEFA $R_{\mathrm{a}}$ and $R_{\mathrm{d}}$ during infusion of AICAR vs the control test. $†$ Significantly lower glucose $R_{\mathrm{a}}$ during AICAR infusion $(p<0.05)$

glycogen synthase kinase (GSK) $3 \alpha / \beta$, GSK $3 \alpha / \beta$, Akt and histone deacetylase 5 (HDAC5) (Cell Signaling, Danvers, MA, USA). Antibodies recognising HDAC5 phosphorylated at S259 and S498 were produced as previously described [23]. Following incubation with appropriate horseradish peroxidase-conjugated secondary antibodies, bands were visualised using a ChemiDoc chemiluminescence detection system (Bio-Rad, Hercules, CA, USA) and quantified using 1D software (Bio-Rad, Hercules, CA, USA).

AMPK activity assays were performed as previously described [23]. Briefly, AMPK $\alpha 1$ and $-\alpha 2$ were immunoprecipitated from $100 \mu \mathrm{g}$ of protein using isoform-specific antibodies $(2 \mu \mathrm{g})$ coupled to $15 \mu \mathrm{l}$ of protein $\mathrm{A}$ beads (Pierce, Rockford, IL, USA). Immune complexes were washed twice with $1 \mathrm{ml}$ of lysis buffer containing $0.5 \mathrm{~mol} / 1$ $\mathrm{NaCl}$, and once with $1 \mathrm{ml}$ of Buffer A $(50 \mathrm{mmol} / 1$ Tris $\mathrm{pH}$ 7.5, $0.1 \mathrm{mmol} / 1$ EGTA, 0.1\% [wt/vol.] 2-mercaptoethanol). Assays were performed in a total volume of $50 \mu \mathrm{l}$ (50 mmol/1 Tris pH 7.5, $0.1 \mathrm{mmol} / 1$ EGTA, $0.1 \%$ 2mercaptoethanol, $10 \mathrm{mmol} / 1 \mathrm{MgCl}_{2}, 0.1 \mathrm{mmol} / 1\left[{ }^{32} \mathrm{P}\right]$ ATP $(\sim 200 \mathrm{cpm} / \mathrm{pmol})$ and $30 \mu \mathrm{mol} / 1$ AMARA peptide (AMARAASAAALARRR). The assays were carried out for $30 \mathrm{~min}$ at $30^{\circ} \mathrm{C}$ and terminated by applying $40 \mu \mathrm{l}$ of the reaction mixture onto P81 papers. Phosphotransferase activity was measured by scintillation counting.

Statistics All data are expressed as mean \pm SEM. To compare tracer kinetics and plasma metabolite concentrations over time, a repeated-measures ANOVA was applied. A Scheffé post hoc test was applied in cases of a significant
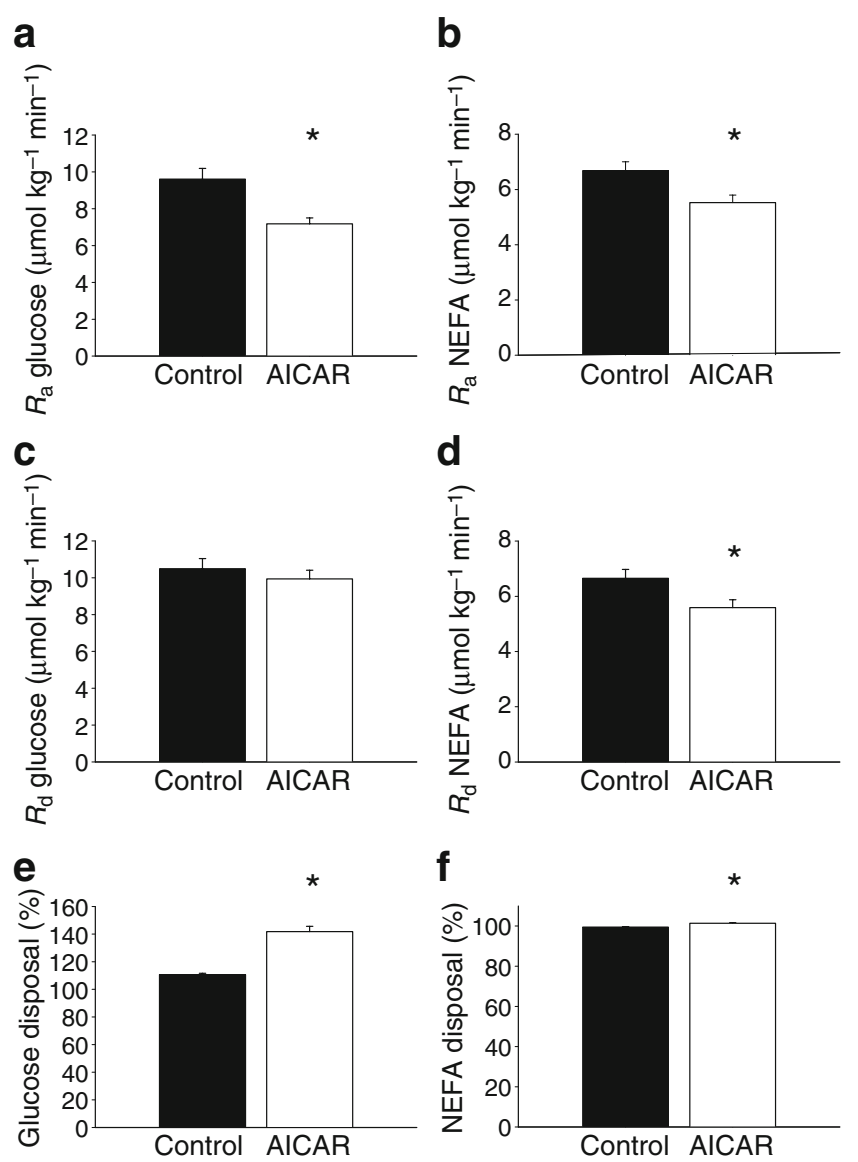

Fig. $2 R_{\mathrm{a}} R_{\mathrm{d}}$ and disposal of glucose (a, c, e) and NEFA (b, d, f) during i.v. AICAR $\left(0.75 \mathrm{mg} \mathrm{kg}^{-1} \mathrm{~min}^{-1}\right)$ or $\mathrm{NaCl}(0.9 \%)$ infusion. Values represent means \pm SEM as calculated between $t=90$ and $t=210$ min (period of AICAR infusion in AICAR test). Disposal is $R_{\mathrm{d}}$ expressed as a percentage of $R_{\mathrm{a}} \cdot{ }^{*} p<0.05$ vs control test 
Table 1 Tracer kinetics as determined at baseline ( $\mathrm{NaCl}$ infusion), and during AICAR or continued $\mathrm{NaCl}(0.9 \%)$ infusion

\begin{tabular}{lcc}
\hline Variable & AICAR $(n=10)$ & Control $(n=10)$ \\
\hline Baseline & & \\
$R_{\mathrm{a}}$ glucose & $10.24 \pm 0.51$ & $11.54 \pm 0.69$ \\
$R_{\mathrm{d}}$ glucose & $12.53 \pm 0.70$ & $13.07 \pm 0.64$ \\
$\% R_{\mathrm{a}} R_{\mathrm{d}}$ glucose & $126.5 \pm 3.8^{\mathrm{a}}$ & $114.7 \pm 1.8$ \\
$R_{\mathrm{a}}$ NEFA & $7.56 \pm 0.73$ & $6.89 \pm 0.46$ \\
$R_{\mathrm{d}}$ NEFA & $7.55 \pm 0.74$ & $6.87 \pm 0.47$ \\
$\% R_{\mathrm{a}} R_{\mathrm{d}}$ NEFA & $99.8 \pm 0.4$ & $99.8 \pm 0.4$ \\
AICAR/NaCl infusion $(t=90$ to $t=210 \mathrm{~min})$ & \\
$R_{\mathrm{a}}$ glucose & $7.18 \pm 0.32^{\mathrm{a}, \mathrm{b}}$ & $9.61 \pm 0.58^{\mathrm{b}}$ \\
$R_{\mathrm{d}}$ glucose & $9.94 \pm 0.47^{\mathrm{b}}$ & $10.49 \pm 0.55^{\mathrm{b}}$ \\
$\% R_{\mathrm{a}} R_{\mathrm{d}}$ glucose & $141.8 \pm 2.6^{\mathrm{a}, \mathrm{b}}$ & $110.6 \pm 1.1^{\mathrm{b}}$ \\
$R_{\mathrm{a}}$ NEFA & $5.52 \pm 0.27^{\mathrm{a}, \mathrm{b}}$ & $6.69 \pm 0.32$ \\
$R_{\mathrm{d}}$ NEFA & $5.59 \pm 0.28^{\mathrm{a}, \mathrm{b}}$ & $6.65 \pm 0.32$ \\
$\% R_{\mathrm{a}} R_{\mathrm{d}}$ NEFA & $101.4 \pm 0.4^{\mathrm{a}, \mathrm{b}}$ & $99.5 \pm 0.2$ \\
\hline
\end{tabular}

Values are means $\pm \operatorname{SEM}(n=10)$. Unless stated otherwise, units are $\mu \mathrm{mol} \mathrm{kg}{ }^{-1} \min ^{-1}$

$\% R_{\mathrm{a}} R_{\mathrm{d}}$, percentage of $R_{\mathrm{a}}$ that is taken up

${ }^{\mathrm{a}} p<0.05$ vs control group; ${ }^{\mathrm{b}} p<0.05$ vs basal values

$F$ ratio, to detect specific differences. For non-timedependent variables, a Student's $t$ test for paired or unpaired (as applicable) observations was used. A $p$ value of less than 0.05 was considered significant.

\section{Results}

Plasma glucose kinetics There were no significant differences in the basal $R_{\mathrm{a}}$ or disappearance $R_{\mathrm{d}}$ between the AICAR and control tests (Figs. 1, 2 and Table 1). In both the AICAR and control tests, plasma glucose $R_{\mathrm{a}}$ and $R_{\mathrm{d}}$ were significantly lower during the intervention period (from $t=105$ to $t=210 \mathrm{~min}$ ) than at baseline (Table 1). However, during AICAR infusion, glucose $R_{\mathrm{a}}$ was significantly lower than $R_{\mathrm{d}}\left(7.18 \pm 0.32\right.$ vs $9.94 \pm 0.47 \mu \mathrm{mol} \mathrm{kg} \mathrm{kg}^{-1} \mathrm{~min}^{-1}, p<$ 0.001 ), while glucose $R_{\mathrm{d}}$ rates were similar in the AICAR and control test $\left(9.94 \pm 0.47 \mathrm{vs} 10.49 \pm 0.55 \mu \mathrm{mol} \mathrm{kg}^{-1} \mathrm{~min}^{-1}\right.$, $p=0.29)$. Consequently, plasma glucose disposal $\left(R_{\mathrm{d}}\right.$ expressed as a percentage of $R_{\mathrm{a}}$ ) during AICAR infusion was significantly greater than during the control infusion when compared with the control test $(141.8 \pm 2.6$ vs $110.6 \pm$ $1.1 \%$, respectively, $p<0.0001$ ).

Plasma NEFA kinetics No significant differences were observed in baseline NEFA $R_{\mathrm{a}}, R_{\mathrm{d}}$ and/or NEFA disposal between tests (Figs. 1, 2 and Table 1). Plasma NEFA $R_{\mathrm{a}}$ and $R_{\mathrm{d}}$ were significantly lower during AICAR infusion than at baseline or during the control test (Figs. 1, 2 and Table 1). Plasma NEFA $R_{\mathrm{d}}$ remained significantly higher than $R_{\mathrm{a}}$ during AICAR infusion $(5.59 \pm 0.28$ vs $5.52 \pm 0.27 \mu \mathrm{mol}$ a

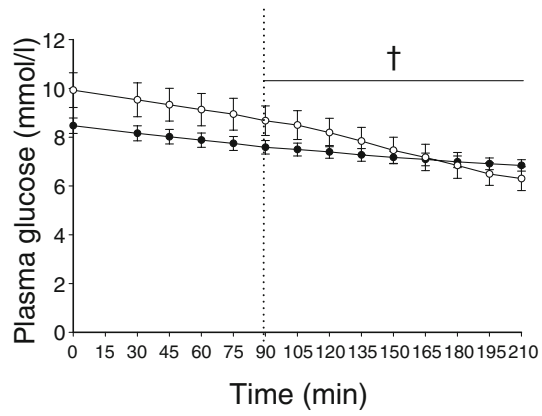

d

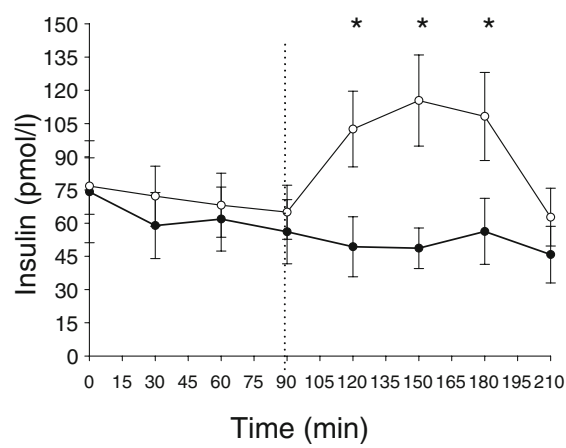

b

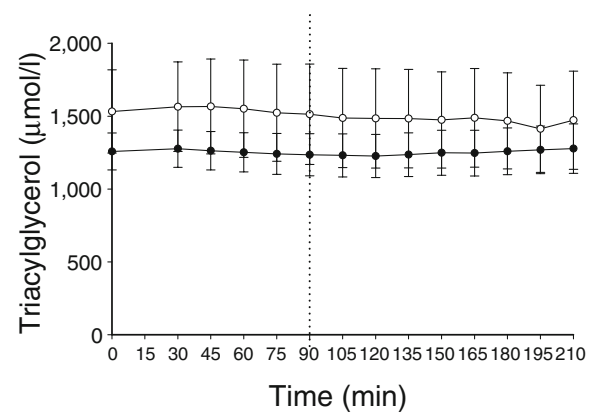

e

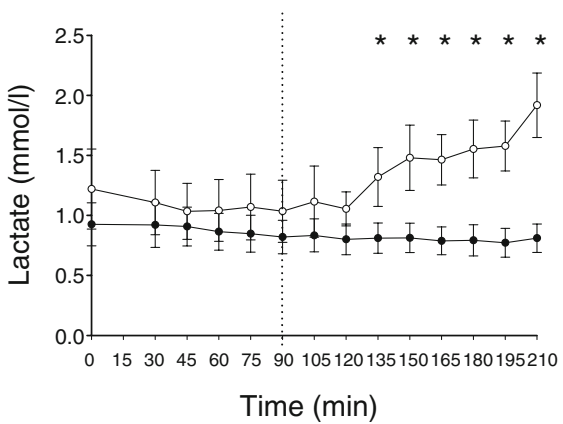

C

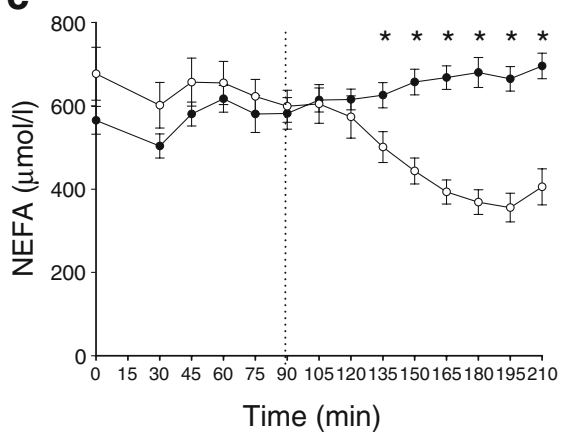

f

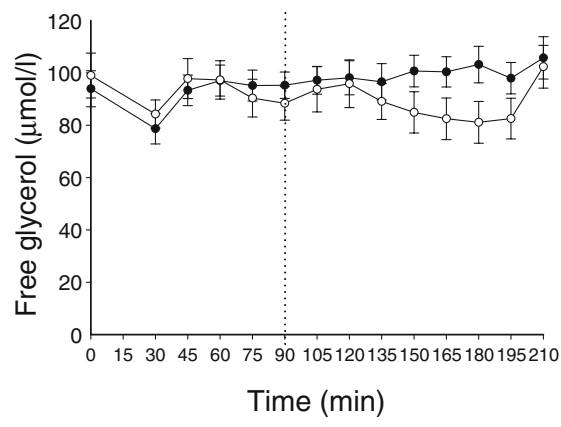

Fig. 3 Plasma glucose (a), triacylglycerol (b), NEFA (c), insulin (d), lactate (e) and free glycerol (f) concentrations during the AICAR (white circles) and control (black circles) tests. Values are means \pm
SEM. Dotted lines mark the beginning of AICAR infusion in the AICAR trial. Infusion of $\mathrm{NaCl}$ was continued in the control trial. $* p<$ 0.05 vs control test; ${ }^{\dagger} \mathrm{p}<0.05$ for rate for vs control test $(p<0.05)$ 
$\left.\mathrm{kg}^{-1} \min ^{-1}, p<0.02\right)$. On average, plasma NEFA disposal rates were significantly higher during AICAR infusion than during the control infusion (101.4 \pm 0.4 and $99.5 \pm 0.2 \%$, respectively, $p<0.001$, Fig. 2 ).

Plasma metabolite concentrations Plasma metabolite concentrations are displayed in Fig. 3. The decline in plasma glucose concentration during the intervention period, corrected for baseline plasma glucose concentration, was significantly greater during AICAR infusion than during the control test $(p<0.0001$ for group interaction). Plasma lactate concentrations increased significantly from $1.03 \pm$ 0.26 to $1.92 \pm 0.27 \mathrm{mmol} / 1$ in response to AICAR infusion and were significantly higher $45 \mathrm{~min}$ after the start of this infusion $(t=135)$ to the end of the infusion compared with the control test $(p<0.02)$. Plasma NEFA concentrations declined significantly during AICAR infusion and were significantly lower $45 \mathrm{~min}$ after the start of the infusion to the end of the infusion compared with the control test $(p<0.002)$. Furthermore, a small but significant rise in circulating plasma insulin concentrations was observed following the onset of AICAR infusion $(p<0.001)$. No significant differences in plasma triacylglycerol or free glycerol concentrations were observed between tests. Plasma AICAR concentrations increased during AICAR infusion up to $161 \pm 11 \mu \mathrm{mol} / 1$ (Fig. 4).

Muscle analyses Western blotting performed on muscle biopsy samples collected prior to and after AICAR administration showed a significant $185 \pm 28 \%$ increase in the ratio of pS79 ACC to unphosphorylated ACC following AICAR administration (Fig. 5). No significant changes were observed in the phosphorylation state of AMPK, AS160, GSK $3 \alpha$, GSK3 $\beta$, HDAC5 (S259 and S498), Akt and ERK. AMPK activity assays showed a $1.7 \pm 0.5$-fold change in AMPK $\alpha 1$ activity $(p=0.16)$, and a $1.01 \pm 0.3$-fold change in AMPK $\alpha 2$ activity (NS) following AICAR infusion.

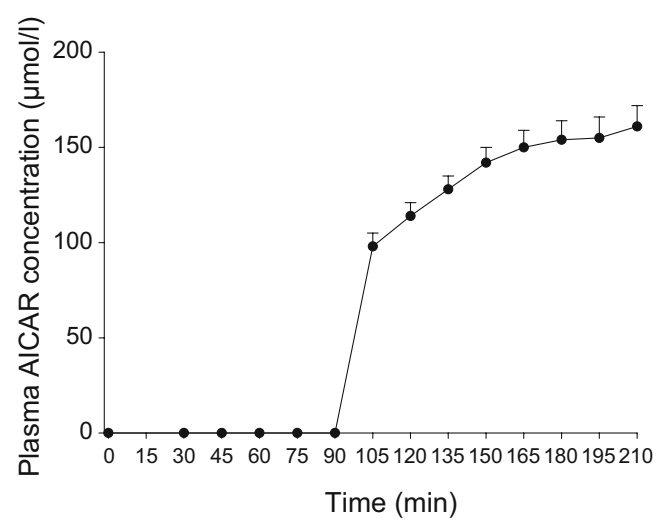

Fig. 4 Plasma AICAR concentrations during i.v. AICAR administration. Values are means \pm SEM
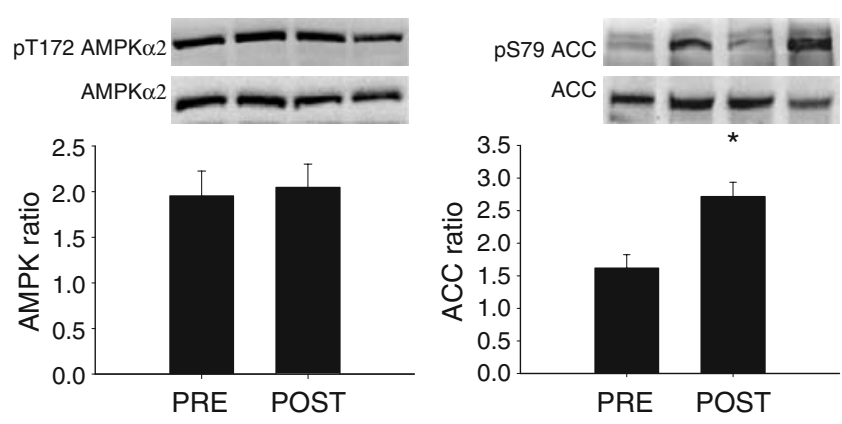

Fig. 5 Skeletal muscle AMPK (a) and ACC (b) phosphorylation prior to (PRE) and after (POST) i.v. AICAR infusion $\left(0.75 \mathrm{mg} \mathrm{kg}^{-1} \mathrm{~min}^{-1}\right)$. The graphs show the ratio of phosphorylated to unphosphorylated protein. Values are means \pm SEM. $* p<0.05$ vs control test

\section{Discussion}

The present study shows that i.v. AICAR infusion in vivo in type 2 diabetic patients inhibits hepatic glucose output while maintaining whole body glucose uptake, thereby lowering plasma glucose concentrations. Furthermore, AICAR infusion is shown to suppress whole body lipolysis, resulting in a decline in plasma NEFA concentration.

The effects of AICAR on glucose metabolism have been studied extensively in rodent models, both in vitro and in vivo. These studies demonstrate that AMPK activation by AICAR stimulates glucose uptake $[2-4,6,7]$ and inhibits hepatic glucose output [5] in an insulin-independent manner. In obese and/or insulin-resistant rodent models, glucose tolerance is improved after long-term AICAR administration [10-12]. Ex vivo studies in human skeletal muscle tissue samples have yielded similar results, demonstrating that AICAR increases glucose transport [13] and fatty acid oxidation [14], which is accompanied by an increase in AMPK phosphorylation and/or activity [13, 14] and ACC phosphorylation [13, 14]. It is evident that it would be of great interest to determine the effects of in vivo AICAR administration in humans. Cuthbertson et al. [19] recently described a twofold increase in 2-deoxyglucose uptake in skeletal muscle after $3 \mathrm{~h}$ of AICAR infusion $\left(10 \mathrm{mg} \mathrm{kg}^{-1} \mathrm{~h}^{-1}\right)$ in young men. However, this was not accompanied by changes in plasma glucose concentration [19]. During a euglycaemic-hyperinsulinaemic clamp in combination with AICAR infusion, whole body glucose uptake (i.e. $M$ value) was slightly increased (7\%) [19].

To date, no study has investigated the effects of AICAR administration on plasma glucose and fatty acid kinetics in vivo in type 2 diabetic patients. In the present study, we demonstrate a strong decline in the rate of appearance of plasma glucose following AICAR infusion $\left(0.75 \mathrm{mg} \mathrm{kg}^{-1}\right.$ $\min ^{-1}$, or $45 \mathrm{mg} \mathrm{kg}^{-1} \mathrm{~h}^{-1}$ ), suggesting that AICAR infusion strongly suppresses hepatic glucose output in type 2 diabetic patients. This is in accordance with previous 
results in obese Zucker rats, in which AICAR infusion was shown to suppress hepatic glucose output [5]. Even though plasma glucose appearance rates declined during AICAR infusion, whole body glucose uptake remained unchanged (Figs. 1, 2). Consequently, glucose disposal (when defined as the percentage of glucose $R_{\mathrm{a}}$ that is taken up from the circulation) was significantly greater during AICAR infusion (Figs. 1, 2). These findings extend the previous observations by Cuthbertson et al. [19] and indicate that AICAR infusion in patients with type 2 diabetes has only a modest impact on plasma glucose uptake but strongly inhibits hepatic glucose output. In contrast to Cuthbertson et al. [19], we observed a significant decline in plasma glucose levels during AICAR infusion. This discrepancy between studies may be attributed to the 4.5-fold higher AICAR dose that was administered and the selection of insulin-resistant type 2 diabetic patients as opposed to healthy, young men.

In the present study we also assessed the effect of AICAR infusion on plasma NEFA kinetics. Activation of AMPK by AICAR has been shown to inhibit lipolysis and lipogenesis in vitro in adipocytes $[8,24,25]$ and in vivo in both lean and insulin-resistant obese rat models [5]. This study is the first to demonstrate that i.v. AICAR infusion $\left(0.75 \mathrm{mg} \mathrm{kg}^{-1} \mathrm{~min}^{-1}\right)$ inhibits the whole body lipolytic rate in type 2 diabetic patients, resulting in a significant decline in circulating plasma NEFA concentrations (Fig. 3). Furthermore, as AMPK activation in the liver also stimulates hepatic fatty acid oxidation [26], it might be assumed that the decline in the rate of appearance of plasma NEFA is also partly due to a greater hepatic extraction and oxidation rate of fatty acids released from the splanchnic area. Altogether, it appears that the effects of AICAR infusion on plasma glucose and NEFA levels in type 2 diabetic patients are mainly exerted through its effects on the liver and adipose tissue, by inhibition of endogenous glucose production, stimulation of hepatic fatty acid oxidation and/or a reduction in whole body lipolysis. Contrary to our expectations, the effect of AICAR infusion on whole body and/or skeletal muscle glucose and NEFA uptake seems to be of less quantitative importance in type 2 diabetic patients.

To investigate the effects of AICAR on AMPK activation in skeletal muscle tissue, we measured potential changes in the phosphorylation state of AMPK and its downstream target, ACC, as a more sensitive marker of AMPK activation [27]. Although we failed to detect a significant increase in AMPK phosphorylation (Fig. 4), we did observe a substantial increase in ACC phosphorylation in muscle biopsy samples collected after $2 \mathrm{~h}$ of AICAR infusion $(185 \pm 28 \%)$. As the ACC phosphorylation state can be used as a more sensitive measure of in vivo AMPK activity, our findings suggest that modest allosteric activation of AMPK had occurred without substantial phosphorylation of AMPK by its kinase. However, this was not supported by the AMPK activity assays, which showed no changes in either AMPK $\alpha 1$ or $-\alpha 2$ activity. Alternatively, it is possible that an unknown kinase that is responsive to AICAR was responsible for the increase in ACC phosphorylation. We did not detect any effect of AICAR infusion on the phosphorylation of other known AMPK substrates, such as AS160, GSK $3 \alpha$, GSK $3 \beta$ and HDAC5 (on S259 and S498). Cuthbertson et al. [19] showed an increase in ERK1/ 2 phosphorylation with AICAR infusion in humans. However, no change was detected in the present study. As such, our data indicate that AICAR infusion in vivo in type 2 diabetic patients only modestly activates AMPK in skeletal muscle tissue. The impact of AICAR infusion on AMPK activation seems to be much greater in adipose and/ or liver tissue. It should be noted that a small but significant increase in circulating plasma insulin concentrations during the AICAR test might have contributed to the observed effects on hepatic glucose output and whole body lipolysis [28]. Future studies using AICAR administration in vivo in humans might consider the use of octreotide to suppress insulin secretion. Furthermore, it should be mentioned that some effects of AICAR may not be AMPK-mediated, especially the effects on hepatic glucose output [29]. As adipose and/or liver tissue samples were not collected, we can only speculate on the impact of AICAR infusion on AMPK activation in hepatic and/or adipose tissue.

In conclusion, i.v. AICAR infusion $\left(0.75 \mathrm{mg} \mathrm{kg}^{-1} \mathrm{~min}^{-1}\right)$ in type 2 diabetic patients inhibits hepatic glucose output, stimulates hepatic fatty acid oxidation and/or reduces whole body lipolysis in vivo, thereby lowering plasma glucose and NEFA concentrations.

Acknowledgements The authors thank A. Jansen Van Roosendaal and M. van Helden (Radboud University Nijmegen Medical Centre) for their practical assistance, S. Kok and A. Blenke from the Department of Clinical Pharmacy (Radboud University Nijmegen Medical Centre) for the preparation of AICAR and tracers, and P. van den Broek (Radboud University Nijmegen Medical Centre), A. Gijsen (Maastricht University) and J. Senden (Maastricht University) for analytical assistance.

Duality of interest The authors declare that there is no duality of interest associated with this manuscript.

Open Access This article is distributed under the terms of the Creative Commons Attribution Noncommercial License which permits any noncommercial use, distribution, and reproduction in any medium, provided the original author(s) and source are credited.

\section{References}

1. Wojtaszewski JF, Nielsen P, Hansen BF, Richter EA, Kiens B (2000) Isoform-specific and exercise intensity-dependent activation of 5'-AMP-activated protein kinase in human skeletal muscle. J Physiol 528:221-226 
2. Merrill GF, Kurth EJ, Hardie DG, Winder WW (1997) AICA riboside increases AMP-activated protein kinase, fatty acid oxidation, and glucose uptake in rat muscle. Am J Physiol 273:E1107-E1112

3. Iglesias MA, Furler SM, Cooney GJ, Kraegen EW, Ye JM (2004) AMP-activated protein kinase activation by AICAR increases both muscle fatty acid and glucose uptake in white muscle of insulin-resistant rats in vivo. Diabetes 53:1649-1654

4. Bergeron R, Russell RR 3rd, Young LH et al (1999) Effect of AMPK activation on muscle glucose metabolism in conscious rats. Am J Physiol 276:E938-E944

5. Bergeron R, Previs SF, Cline GW et al (2001) Effect of 5aminoimidazole-4-carboxamide-1-beta-d-ribofuranoside infusion on in vivo glucose and lipid metabolism in lean and obese Zucker rats. Diabetes 50:1076-1082

6. Hayashi T, Hirshman MF, Kurth EJ, Winder WW, Goodyear LJ (1998) Evidence for 5' AMP-activated protein kinase mediation of the effect of muscle contraction on glucose transport. Diabetes 47:1369-1373

7. Kurth-Kraczek EJ, Hirshman MF, Goodyear LJ, Winder WW (1999) 5' AMP-activated protein kinase activation causes GLUT4 translocation in skeletal muscle. Diabetes 48:1667-1671

8. Sullivan JE, Brocklehurst KJ, Marley AE, Carey F, Carling D, Beri RK (1994) Inhibition of lipolysis and lipogenesis in isolated rat adipocytes with AICAR, a cell-permeable activator of AMPactivated protein kinase. FEBS Lett 353:33-36

9. Iglesias MA, Ye JM, Frangioudakis G et al (2002) AICAR administration causes an apparent enhancement of muscle and liver insulin action in insulin-resistant high-fat-fed rats. Diabetes 51:2886-2894

10. Song XM, Fiedler M, Galuska D et al (2002) 5-Aminoimidazole4-carboxamide ribonucleoside treatment improves glucose homeostasis in insulin-resistant diabetic $(o b / o b)$ mice. Diabetologia 45:56-65

11. Pold R, Jensen LS, Jessen N et al (2005) Long-term AICAR administration and exercise prevents diabetes in ZDF rats. Diabetes 54:928-934

12. Buhl ES, Jessen N, Pold R et al (2002) Long-term AICAR administration reduces metabolic disturbances and lowers blood pressure in rats displaying features of the insulin resistance syndrome. Diabetes 51:2199-2206

13. Koistinen HA, Galuska D, Chibalin AV et al (2003) 5-Aminoimidazole carboxamide riboside increases glucose transport and cell-surface GLUT4 content in skeletal muscle from subjects with type 2 diabetes. Diabetes 52:1066-1072

14. Steinberg GR, Smith AC, Van Denderen BJ et al (2004) AMPactivated protein kinase is not down-regulated in human skeletal muscle of obese females. J Clin Endocrinol Metab 89:4575-4580

15. Sriwijitkamol A, Coletta DK, Wajcberg E et al (2007) Effect of acute exercise on AMPK signaling in skeletal muscle of subjects with type 2 diabetes: a time-course and dose-response study. Diabetes 56:836-848
16. Musi N, Fujii N, Hirshman MF et al (2001) AMP-activated protein kinase (AMPK) is activated in muscle of subjects with type 2 diabetes during exercise. Diabetes 50:921-927

17. Henin N, Vincent MF, Gruber HE, Van den Berghe G (1995) Inhibition of fatty acid and cholesterol synthesis by stimulation of AMP-activated protein kinase. FASEB J 9:541-546

18. Al-Khalili L, Krook A, Zierath JR, Cartee GD (2004) Prior serum- and AICAR-induced AMPK activation in primary human myocytes does not lead to subsequent increase in insulinstimulated glucose uptake. Am J Physiol Endocrinol Metab 287:E553-E557

19. Cuthbertson DJ, Babraj JA, Mustard KJ et al (2007) 5Aminoimidazole-4-carboxamide 1-beta-d-ribofuranoside acutely stimulates skeletal muscle 2-deoxyglucose uptake in healthy men. Diabetes 56:2078-2084

20. Durnin JV, Womersley J (1974) Body fat assessed from total body density and its estimation from skinfold thickness: measurements on 481 men and women aged from 16 to 72 years. Br J Nutr 32:77-97

21. Smits P, Lenders JW, Thien T (1990) Caffeine and theophylline attenuate adenosine-induced vasodilation in humans. Clin Pharmacol Ther 48:410-418

22. Abumrad NN, Rabin D, Diamond MP, Lacy WW (1981) Use of a heated superficial hand vein as an alternative site for the measurement of amino acid concentrations and for the study of glucose and alanine kinetics in man. Metabolism 30:936-940

23. McGee SL, van Denderen BJ, Howlett KF et al (2008) AMPactivated protein kinase regulates GLUT4 transcription by phosphorylating histone deacetylase 5. Diabetes 57:860-867

24. Dagon Y, Avraham Y, Berry EM (2006) AMPK activation regulates apoptosis, adipogenesis, and lipolysis by eIF2alpha in adipocytes. Biochem Biophys Res Commun 340:43-47

25. Gaidhu MP, Fediuc S, Ceddia RB (2006) 5-Aminoimidazole-4carboxamide-1-beta-d-ribofuranoside-induced AMP-activated protein kinase phosphorylation inhibits basal and insulin-stimulated glucose uptake, lipid synthesis, and fatty acid oxidation in isolated rat adipocytes. J Biol Chem 281:25956-25964

26. Viollet B, Foretz M, Guigas B et al (2006) Activation of AMPactivated protein kinase in the liver: a new strategy for the management of metabolic hepatic disorders. J Physiol 574:41-53

27. Winder WW, Wilson HA, Hardie DG et al (1997) Phosphorylation of rat muscle acetyl-CoA carboxylase by AMP-activated protein kinase and protein kinase A. J Appl Physiol 82:219-225

28. Wang CZ, Wang Y, Di A et al (2005) 5-Amino-imidazole carboxamide riboside acutely potentiates glucose-stimulated insulin secretion from mouse pancreatic islets by KATP channeldependent and -independent pathways. Biochem Biophys Res Commun 330:1073-1079

29. Vincent MF, Erion MD, Gruber HE, Van den Berghe G (1996) Hypoglycaemic effect of AICAriboside in mice. Diabetologia 39:1148-1155 